\title{
FIRST OBSERVATION \\ OF VISIBLE LUMINESCENCE FROM TRIVALENT GADOLINIUM
}

\author{
R.T. Wegh and A. MEIJERINK \\ Debye Institute, Utrecht University \\ P.O. Box 80 000, 3508 TA Utrecht, The Netherlands
}

The ${ }^{6} G_{J} \rightarrow{ }^{6} P_{J}$ emission for $\mathrm{Gd}^{3+}$ in $\mathrm{LiYF}_{4}$ around $600 \mathrm{~nm}$ is reported. As far as we are aware, this is the first observation of visible luminescence from trivalent gadolinium.

PACS numbers: 78.20.Wc, 42.62.Fi

\section{Introduction}

The development of new phosphors for vacuum ultraviolet (VUV) excitation is an important new challenge in the field of luminescent materials research. VUV phosphors can be applied in mercury free fluorescent tubes and in plasma display panels, in combination with a noble gas discharge. The xenon dimer discharge, which gives the highest efficiency of all noble gases, is still less efficient than the conventional mercury discharge. Therefore a phosphor with a quantum efficiency higher than $100 \%$ is needed, in other words: more than one visible photon should be obtained per absorbed VUV photon. One of the challenges in this research area is to find such a VUV phosphor, a so-called quantum cutter. For rare earth ions the phenomenon of quantum cutting is known [1], but based on the current knowledge no efficient quantum cutter in the visible is possible. However, the energy levels of rare earth ions in the VUV region (above $50000 \mathrm{~cm}^{-1}$ ) have hardly been investigated. The high energy of the VUV photons from a xenon dimer discharge $\left(172 \mathrm{~nm}, 58100 \mathrm{~cm}^{-1}\right)$ makes it possible (in theory) to obtain quantum cutting in the visible.

The research on quantum cutters will focus on the luminescence of rare earth ions under VUV excitation. First, the energy levels in the VUV will be resolved for a number of rare earth ions. The first ions to be investigated will be those ions which are able to give an efficient emission in the visible, either directly or after energy transfer, viz. $\mathrm{Nd}^{3+}, \mathrm{Sm}^{3+}, \mathrm{Eu}^{3+}, \mathrm{Gd}^{3+}, \mathrm{Tb}^{3+}, \mathrm{Ho}^{3+}$ and $\mathrm{Er}^{3+}$. To resolve the energy levels in the VUV the lanthanides will be incorporated in fluoride lattices (e.g. $\mathrm{LiYF}_{4}$ and $\mathrm{LaF}_{3}$ ). In these host lattices the excited states $\left(4 f^{n-1} 5 d\right.$ and charge transfer) which can interfere with the energy levels of the 
$4 f^{n}$ configuration are at the highest possible energies. Next, it will be investigated if an efficient quantum cutter is possible for one of the rare earth ions studied. To this extent the emission spectra under VUV excitation will be analyzed. With the aid of Judd-Ofelt theory it can be determined if an efficient quantum cutter in the visible is feasible.

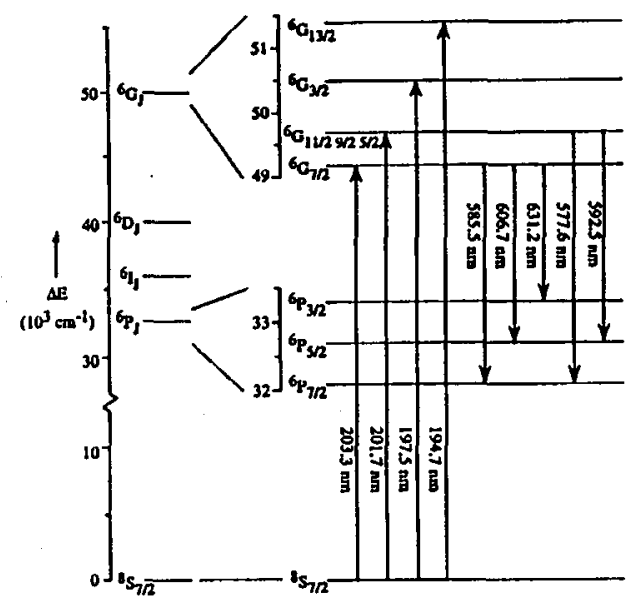

Fig. 1. Energy level scheme in the range $0-50000 \mathrm{~cm}^{-1}$ for $\mathrm{Gd}^{3+}$ in fluoride lattices. Note the breaks in the energy scale. The arrows correspond to lines in the excitation spectrum in Fig. 2 and the emission spectrum in Fig. 3.

In this paper the first results on $\mathrm{Gd}^{3+}$ in $\mathrm{LiYF}_{4}$ are presented. The schematic energy level diagram of $\mathrm{Gd}^{3+}\left(4 f^{7}\right)$ as far as it is known is given in Fig. 1 (left side) [2]. The $\mathrm{Gd}^{3+}$ emission due to the ${ }^{6} P_{7 / 2} \rightarrow{ }^{8} S_{7 / 2}$ transition is well known and is situated around $312 \mathrm{~nm}$. Up until now, only emission to the ${ }^{8} S_{7 / 2}$ ground state has been reported for $\mathrm{Gd}^{3+}$, including the ${ }^{6} G_{J} \rightarrow{ }^{8} S_{7 / 2}$ emission around $200 \mathrm{~nm}$, which has been found in several host lattices [3]. These emissions are all in the ultraviolet region. Ilowever, on the basis of the energy level scheme of $\mathrm{Gd}^{3+}$ one can expect a visible emission in the orange/red due to the ${ }^{6} G_{J} \rightarrow{ }^{6} P_{J}$ transition, followed by emission of a second photon from the ${ }^{6} P_{J}$ level. It will be shown that this visible emission can indeed be observed.

\section{Experimental}

The polycrystalline sample of $\mathrm{LiYF}_{4}: \mathrm{Gd}^{3+} 10 \mathrm{~mol} \%$ was prepared by firing a mixture of $\mathrm{LiF}, \mathrm{YF}_{3}$ and $\mathrm{GdF}_{3}$ at $550^{\circ} \mathrm{C}$ in a nitrogen atmosphere. $\mathrm{GdF}_{3}$ was prepared by precipitation of $\mathrm{Gd}^{3+}$ in an acidic solution by $\mathrm{NI}_{4} \mathrm{~F}$. Neutron activation analysis showed that the $\mathrm{Gd}_{2} \mathrm{O}_{3}$ used contained $1 \mathrm{ppm} \mathrm{of} \mathrm{Eu}^{3+}$. The other starting materials contained no significant amounts of rare earth ions as impurities. The polycrystalline sample of $\mathrm{LiYF}_{4}: \mathrm{Eu}^{3+} 1 \mathrm{~mol} \%$ was prepared in the same way.

The excitation and emission spectra were recorded at room temperature with a Spex 1680 spectroluorometer, equipped with $0.22 \mathrm{~m}$ double monochromators. 
The excitation source for the $\mathrm{LiYF}_{4}: \mathrm{Gd}^{3+}$ measurements was a $\mathrm{D}_{2}$-lamp (Hamamatsu L1835, $150 \mathrm{~W}$ ), for the $\mathrm{LiYF}_{4}: \mathrm{Eu}^{3+}$ a Xe-lamp (Ushio UXL, $450 \mathrm{~W}$ ) was used. The signal was detected with a cooled IIamamatsu R928 photomultiplier tube.

\section{Results and discussion}

Figure 2 sliows the excitation spectrum in the ${ }^{8} S_{7 / 2} \rightarrow{ }^{6} G_{J}$ region of the $\mathrm{Gd}^{3+}$ emission at $311.0 \mathrm{~nm}$ for $\mathrm{Gd}^{3+}$ in $\mathrm{LiYF}_{4}$ at $300 \mathrm{~K}$. The assignment of the lines is made based on the positions of the different energy levels found for $\mathrm{LaF}_{3}: \mathrm{Gd}^{3+}[2]$. The resolution of the used apparatus was too low to observe all transitions to different Stark levels of one term separately. We were not able to assign the peaks at $190.6,189.2$ and $187.2 \mathrm{~nm}$ because the term symbol of the final state is not known yet. In Fig. 1 (right side) the energy level scheme for $\mathrm{Gd}^{3+}$ in $\mathrm{LiYF}_{4}$ derived from the present and previous observations is depicted [4]. Upon

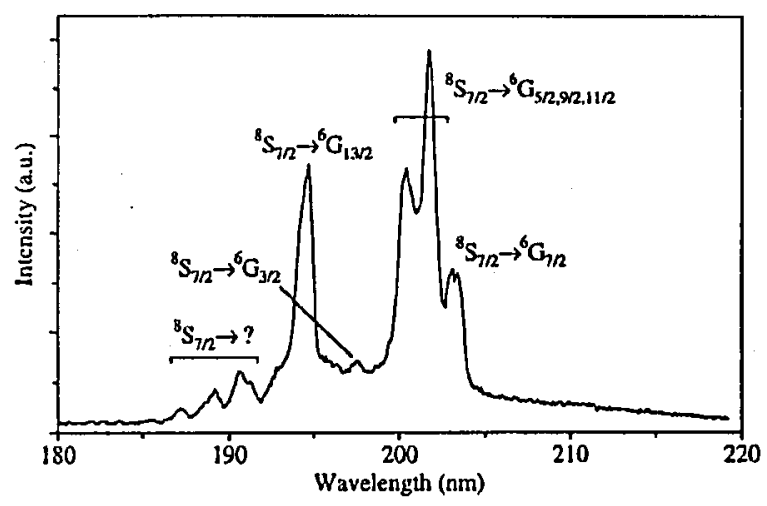

Fig. 2. ${ }^{8} S_{7 / 2} \rightarrow{ }^{6} G_{J}$ excitation spectrum of $\mathrm{LiYF}_{4}: \mathrm{Gd}^{3+} 10 \%$ monitoring ${ }^{6} P_{7 / 2} \rightarrow$ ${ }^{8} S_{7 / 2}$ emission $(311.0 \mathrm{~nm})$ at $300 \mathrm{~K}$.

excitation in the ${ }^{6} G_{J}$ levels, ${ }^{6} G_{J} \rightarrow{ }^{6} P_{J}$ emission lines were observed in the visible, viz. around $600 \mathrm{~nm}$. This can be seen in Fig. 3, in which the emission spectrum at $300 \mathrm{~K}$ is given (upper trace). The emissions at 577.6, 585.5, 592.5, 606.7 and 631.2 $\mathrm{nm}$ are assigned to ${ }^{6} G_{J} \rightarrow{ }^{6} P_{J}$ transitions of $\mathrm{Gd}^{3+}$, and are also indicated in Fig. 1. The $585.5,606.7$ and $631.2 \mathrm{~nm}$ peaks are transitions from ${ }^{6} G_{7 / 2}$ to the different ${ }^{6} P_{J}$ terms. The 577.6 and $592.5 \mathrm{~nm}$ emissions originate from higher ${ }^{6} G_{J}$ terms, which are thermally populated at room temperature. The emission wavelengths agree very wcll with the calculated energy differences between the measured ${ }^{6} G_{J}$ energy values (Fig. 2) and the ${ }^{6} P_{J}$ energy levels for $\mathrm{LiYF}_{4}: \mathrm{Gd}^{3+}$ from [4]. As far as we are aware, the ${ }^{6} G_{J} \rightarrow{ }^{6} P_{J}$ emission is the first observed visible luminescence from $\mathrm{Gd}^{3+}$.

The emission lines at 590.4 and $613.8 \mathrm{~nm}$ are assigned to the ${ }^{5} D_{0} \rightarrow{ }^{7} F_{1}$ and ${ }^{5} D_{0} \rightarrow{ }^{7} F_{2}$ transition, respectively, of $\mathrm{Eu}^{3+}$ impurities originating from the starting compound $\mathrm{Gd}_{2} \mathrm{O}_{3}$. This becomes evident by comparing the emission spectrum of $\mathrm{LiYF}_{4}: \mathrm{Gd}^{3+}$ with the emission spectrum of $\mathrm{LiYF}_{4}: \mathrm{Eu}^{3+}$ in the same region 


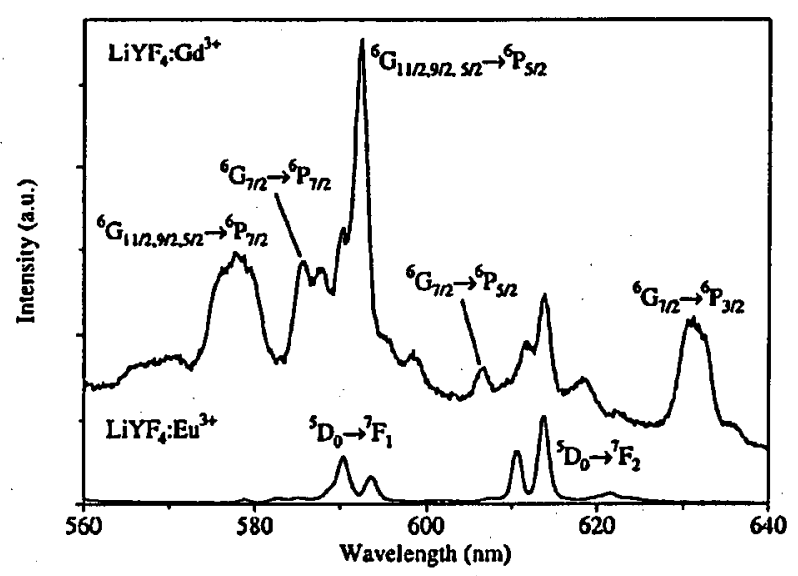

Fig. 3. Upper trace: ${ }^{6} G_{J} \rightarrow{ }^{6} P_{J}$ emission spectrum of $\mathrm{LiYF}_{4}: \mathrm{Gd}^{3+} 10 \%$ upon ${ }^{8} S_{7 / 2} \rightarrow$. ${ }^{6} G_{J}$ excitation $(201.7 \mathrm{~nm})$ at $300 \mathrm{~K}$. Lower trace: ${ }^{5} D_{0} \rightarrow{ }^{7} F_{J}$ emission spectrum of $\mathrm{LiYF}_{4}: \mathrm{Eu}^{3+} 1 \%$ upon excitation at $222.7 \mathrm{~nm}$ at $300 \mathrm{~K}$.

(Fig. 3, lower trace). Although the $\mathrm{Eu}^{3+}$ concentration is very low, the strong ${ }^{5} D_{0} \rightarrow{ }^{7} F_{1,2}$ emissions are present because of the efficient energy transfer from the ${ }^{6} P_{7 / 2}$ level of $\mathrm{Gd}^{3+}$ to the ${ }^{5} H_{J}$ levels of $\mathrm{Eu}^{3+}$. It should be mentioned that the ${ }^{6} G_{11 / 2,9 / 2,5 / 2} \rightarrow{ }^{6} P_{3 / 2}$ transitions of $\mathrm{Gd}^{3+}$ are expected to be present at $c a$. $614 \mathrm{~nm}$, but cannot be observed in the emission spectrum of $\mathrm{LiYF}_{4}: \mathrm{Gd}^{3+}$ because of the $\mathrm{Eu}^{3+}$ emission in the same region.

Just as for $\mathrm{LiYF}_{4}: \mathrm{Gd}^{3+}$, an excitation spectrum in the area around $200 \mathrm{~nm}$ was recorded for $\mathrm{LiYF}_{4}: \mathrm{Eu}^{3+}$. The highest energetic level detected was at $222.7 \mathrm{~nm}$. This was used as excitation wavelength for the emission spectrum of $\mathrm{LiYF}_{4}: \mathrm{Eu}^{3+}$ in Fig. 3, lower trace. The fact that the emissions at 592.5, 577.6, 585.5 and $631.2 \mathrm{~nm}$ in Fig. 3 upper trace $\left(\mathrm{LiYF}_{4}: \mathrm{Gd}^{3+}\right)$ are not present in the lower trace $\left(\mathrm{LiYF}_{4}: \mathrm{Eu}^{3+}\right)$ is a proof that these lines cannot be due to energy transfer to $\mathrm{Eu}^{3+}$ followed by emission. Other rare earth ions which could be present as impurities and give emission in the region around $600 \mathrm{~nm}$ are $\mathrm{Tb}^{3+}, \mathrm{Sm}^{3+}, \mathrm{Dy}^{3+}$ and $\mathrm{Ho}^{3+}$, but there is no agreement between Fig. 3 upper trace and the emission spectra of these ions in $\mathrm{LiYF}_{4}$. Besides, if $\mathrm{Tb}^{3+}$ were present in the $\mathrm{LiYF}_{4}: \mathrm{Gd}^{3+}$ sample the lowest parity allowed $4 f^{\top} 5 d^{1}$ band should be present in the excitation spectrum at $215 \mathrm{~nm}$, which is not the case.

Upon excitation in the ${ }^{6} G_{J}$ levels, also the ${ }^{6} G_{J} \rightarrow{ }^{6} I_{J}$ emission is observed in the near infrared, viz. around $750 \mathrm{~nm}$. This observation supports the assignment of the emissions around $600 \mathrm{~nm}$ to $\mathrm{Gd}^{3+}$.

Upon ${ }^{8} S_{7 / 2} \rightarrow{ }^{6} G_{J}$ excitation quantum cutting occurs because the ${ }^{6} G_{J} \rightarrow$ ${ }^{6} P_{J}$ emission is followed by the ${ }^{6} P_{J} \rightarrow{ }^{8} S_{7 / 2}$ emission of $\mathrm{Gd}^{3+}$ around $311 \mathrm{~nm}$, which is in the UV. A quantum cutter in the visible can be constructed by using the energy transfer from the ${ }^{6} P_{J}$ levels of $\mathrm{Gd}^{3+}$ to $\mathrm{Eu}^{3+}$ or $\mathrm{Tb}^{3+}$. These ions subsequently give an efficient emission in the red or in the green, respectively. However, it should be noted that the ${ }^{6} G_{J} \rightarrow{ }^{6} P_{J}$ emission of $\mathrm{Gd}^{3+}$ has a low 
efficiency. This can be derived from the fact that upon excitation in the ${ }^{6} G_{J}$ levels the ${ }^{6} G_{J} \rightarrow{ }^{6} P_{J}$ emission is very weak in comparison with the ${ }^{6} P_{J} \rightarrow{ }^{8} S_{7 / 2}$ emission.

In the near future the measurements will be extended into the VUV region down to $c a .150 \mathrm{~mm}$, for $\mathrm{Gd}^{3+}$ as well as for a number of other trivalent rare earth ions. The high cnergetic $4 f$ levels will also be calculated, so that assignments to term symbols can be made. The possibilities for visible emission from these high energetic levels resulting in efficient quantum cutting in the visble will be investigated.

\section{Acknowledgments}

The work described here was supported by the Netherlands Foundation for Chemical Research (SON), with financial aid from the Netherlands Organization for Scientific Rescarch (NWO) and the Netherlands Foundation for Technical Research (STW).

\section{References}

[1] J.L. Sommerdijk, A. Bril, A.W. de Jager, J. Lumin. 8, 341 (1974); W.W. Piper, J.A. DeLuca, F.S. Ham, J. Lumin. 8, 314 (1974).

[2] W.T. Carnall, G.L. Goodman, K. Rajnak, R.S. Rana, $A N L-88-8$, Argonne National Laboratory, Argonne (Illinois) 1988, p. 142.

[3] L.II. Brixner, G. Blasse, Chem. Phys. Lelt. 157, 283 (1989).

[4] A.J. de Vries, M.F. Hazenkamp, G. Blasse, J. Lumin. 42, 275 (1988). 